\title{
Atypical hyperglycemia presentation suggests considering a diagnostic of other types of diabetes: first reported GCK-MODY in Perú
}

\author{
Juan Carlos Lizarzaburu-Robles ${ }^{1,2^{*}}$ (D), Juan Carlos Gomez-de-la-Torre ${ }^{3}$, María del Carmen Castro-Mujica ${ }^{3}$,
} Flor Vento', Sofia Villanes ${ }^{1}$, Elizabeth Salsavilca ${ }^{2}$ and Chris Guerin ${ }^{4}$

\begin{abstract}
Background: Prevalence of maturity-onset diabetes of the young (MODY) is estimated between 1 and 2\% of all diabetes cases. In Latin-America little information has been described about the frequency of the disease, perhaps due to limited access to genetic studies.

Case presentation: We present the case of a male patient with a history of two years of fatigue, mild hyperglycemia and intermittent polyuria, accompanied by a recent history of weight loss. He was diagnosed initially as type 2 diabetes, but in the follow-up as a patient with type 1 diabetes. He required relatively low doses of insulin and was evaluated in the endocrinology service at a hospital in Lima. The results of glucose, insulin and C-peptide in the oral glucose tolerance test (OGTT) performed were not consistent with a type 1 diabetes. Moreover, the age of the patient and the clinical characteristics did not strongly suggest a diagnosis of type 2 diabetes either. These clinical features had prompted us to carry out the genetic study. The genetic test performed with a genetic MODY panel through a massive sequencing. Heterozygous pathogenic for a variant in GCK gene was found c.629C>T p.(Thr210Met). His parents were negative for this variant after performed the genetic test.

Conclusions: This is the first case of MODY for a pathogenic variant in the GCK gene reported in Perú. The genetic evaluation of a clinical suspicion of MODY is important to confirm the diagnosis and establish an adequate treatment in patients.
\end{abstract}

Keywords: Hyperglycemia, Diabetes, GCK-MODY, Latin-America

\section{Background}

Maturity-Onset Diabetes of the Young (MODY) is a rare monogenic disease which accounts for $1-2 \%$ of all diabetes cases [1, 2]. Recently 14 genes associated with MODY have been proposed and the clinical characteristics differ according to the genetic etiology [3]. MODY should be suspected in non-obese subjects, onset before 25 years with mild hyperglycemia and absence of Diabetic ketoacidosis (DKA) [1, 2, 4]. GCK-MODY or MODY2 is one of the most frequent subtypes described

\footnotetext{
* Correspondence: juancarlosliro@yahoo.com

${ }^{1}$ Hospital Central de la Fuerza Aérea del Perú, Lima, Peru

${ }^{2}$ Asociación para la Prevención, Educación e Investigación en Diabetes APREDIAB, Lima, Peru

Full list of author information is available at the end of the article
}

and is caused by mutations in the GCK gene inherited in an autosomal dominant manner. It is due to mutations in the GCK gene encoding glucokinase, which catalyzes the conversion of glucose to glucose-6-phosphate, an important step in glucose metabolism and the regulation of insulin secretion $[3,5]$.

To date, over 600 different GCK-MODY mutations have been reported and it has been described in the literature in a variety of ethnic groups, most of them in Europeans countries (Italy, France, United Kingdom and Spain, according to the literature) and in North America [1, 3, 5-7]. There is little information about the frequency of MODY in Latin America, and it is lower when we try to find information in countries with 
Native-American or American Indian population. Nevertheless, MODY may be more frequent than previously assumed. Also, the proportion of cases caused by a "de novo" pathogenic variant is unknown for most MODY-related genes. There are a limited number of case reports which describe de novo variants in GCK gene [8]. We report the first case of MODY with a pathogenic variant $G C K$, with a complete genetic analysis, in Perú.

\section{Case presentation}

A 15 years old male diagnosed with type 2 diabetes was referred to an endocrinology outpatient clinic. He was diagnostic at age 13 with an A1c control in $6.8 \%$ and initiated treatment with metformin twice a day. After two years of irregular follow up, the patient presented with history of $2 \mathrm{~kg}$ weight loss, fatigue, mild polydipsia and polyuria but without signs of insulin resistance, such as acanthosis nigricans and/ or obesity. His weight was 52 $\mathrm{kg}$ (BMI between the 10th and 25th percentiles for age and gender), $\mathrm{Hb}: 14.6 \mathrm{~g} / \mathrm{dL}$, fasting glucose: $132 \mathrm{mg} / \mathrm{dl}$, $\mathrm{Hb}$ A1c: $6.4 \%$, creatinine clearance: $181.61 \mathrm{ml} / \mathrm{min}, \mathrm{C}-$ peptide: $1.63 \mathrm{nmol} / \mathrm{L}$, total cholesterol:166, LDL: 114.2 $\mathrm{mg} / \mathrm{dl}$, Triglycerides: $64 \mathrm{mg} / \mathrm{dl}$ and HDL: $39 \mathrm{mg} / \mathrm{dl}$. Also, he had TSH: $1.43 \mathrm{mIU} / \mathrm{L}$ and FT4: $1.21 \mathrm{~m} \mu \mathrm{g} / \mathrm{dl}$. He had Glutamic acid decarboxylase (GAD) antibodies and antiislet cell antibodies which were negative. In his medical history, his birth weight was $3.06 \mathrm{~kg}$ with no family first degree relative with history of Diabetes. We decided to initiate insulin treatment (12 units/day of Levemir and 01unit of pre-prandial lispro) with good clinical response. The patient did not demonstrate hypoglycemia during this period. Both situations suggested the diagnostic of type 1 diabetes and the probability that he was on a spontaneous period of partial clinical remission (honeymoon phase) $[9,10]$. In the follow-up period over the next 6 months, the insulin requirement did not change, and he maintained good glucose control levels (Fig. 1a). Hb A1c control was 6.3\%.

The low insulin-dose requirement in a long time and his non-acute presentation, in the childhood, of diabetes was unusual for type 1 diabetes. We decide to request an Oral Glucose Tolerance Test (OGTT) with measure of Glucose $(\mathrm{mg} / \mathrm{dl})$, insulin $(\mathrm{uUI} / \mathrm{ml})$ and C-peptide

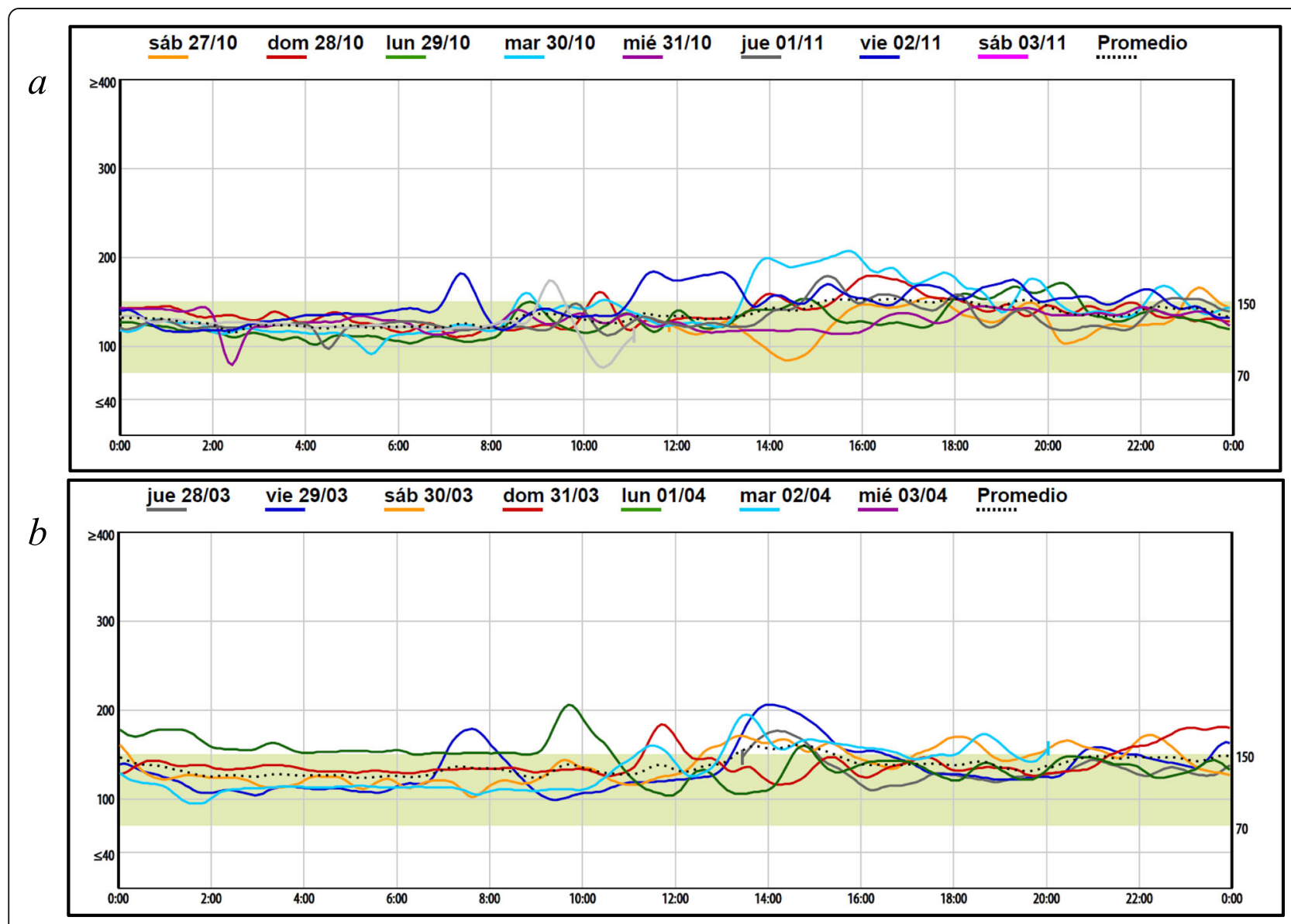

Fig. 1 Patient glucose-monitoring (iPro2) with Insulin (a) and oral agents (b) Dash line ( $\cdots$ ) Represent one week references glycemic control 
$(\mathrm{ng} / \mathrm{ml})$ to evaluate pancreatic response. The following results for the test we see in the Fig. 2.

These results were not typical of either type 1 or type 2 diabetes and supported further evaluation. In addition, we performed an OGTT on his parents, with normal results. We considered appropriate to perform a test for diagnosis of MODY. MODY panel was performed in the next follow up, by next generation sequencing identifying a pathogenic variant c.629C $>\mathrm{T}$ p.(Thr210Met). in heterozygous in GCK gene confirmed by Sanger sequencing according to the American College of Medical Genetics (Fig. 3). However, this variant has been previously described as associated with MODY diabetes $[11,12]$. The biochemical studies show this variant causes the reduction of GCK enzyme activity. This result confirmed the diagnosis of GCK-MODY. The specific molecular analysis for GCK also was performed in his parents. The result was negative for this variant, which suggested that it was a "de novo" variant.

With the result of genetic analysis, we suspended insulin. We decided to initiate metformin $(850 \mathrm{mg})$ twice/ day. The clinical response was excellent as well as the initial treatment (Fig. 1b). We also suggested life-style change with nutritional follow-up.

In the follow-up period to asses control, continuous glucose monitoring was performed to evaluate glucose levels. We see the initial response to insulin treatment during this period in Fig. 1a. A second report of continuous glucose monitoring was performed during oral medication treatment (Fig. 1b). Currently, the patient continues with only oral medication (metformin), and he increased his weigh with optimal clinical control. His most recent $\mathrm{Hb} \mathrm{A} 1 \mathrm{c}$ was $6.2 \%$.

\section{Discussion}

MODY is considered an infrequent disease, and it has been described in several populations and ethnic groups worldwide, more commonly in Europe and North America [1, 5, 7]. A recent publication about GCK-MODY in the US National Monogenic Diabetes Registry, shows that the majority of Registry participants with a GCK-MODY phenotype selfidentified as Caucasian and there was underrepresentation of a number of ethnic minorities when compared to the greater US population and ethnicity-specific diabetes rates [5].
This is the first reported case in Perú, and in a MestizoPeruvian ethnic group, which consist in a population with Native-American and European ancestries [13]. Other countries in Latin America, such as Argentina and Chile, also have reported cases mainly associated with GCK-MODY, which seems to be frequent in our region $[6,7,14]$. It should be noted that not all countries in Latin-American have the same ethnic groups.

Clinical suspicion should be our first step in the diagnosis of this type of diabetes $[1,2,4]$. In our case, initially we assume a Type $1 \mathrm{DM}$ in a period of partial clinical remission or honeymoon phase. As it is known, insulin requirement decreases during this period $[9,10]$. Identifying maturity-onset diabetes of the young (MODY) in pediatric populations is difficult. Misdiagnosis and unnecessary insulin treatment are commonly used [15]. However, the low doses insulin requirement in a long period of time, more than 06 months, and the absence of DKA diminished the possibility of type 1 diabetes [16]. On the other hand, the age at diagnosis, the absence of relatives with type 2 diabetes and obesity reduce the probability of type 2 diabetes. Treatment with metformin was considered as a benefit to improve insulin sensitivity $[17,18]$, because according to the TTOG performed (Fig. 2), the patient presented an insulin test profile that suggested insulin resistance.

Molecular genetic testing to determine the gene associated with MODY can include gene panels or unique gene analysis, as well as exome sequencing [3]. In our patient, the absence of previous reported cases in Perú and the little information about frequency of MODY types in the Latino population, led us to the determination of carrying out a MODY Panel genetic analysis. MODY GCK gene-variant suspicion was confirmed. GCK mutations cause a resetting of the glucose and is associated with mild hyperglycemia and low ranges of HbA1c (less than 7.6\%), while the secretion and regulation of insulin is not completely altered $[3,4,19]$. The hyperglycemia in GCK-MODY is present throughout life but is usually asymptomatic and only detected when blood glucose is measured incidentally [20]. Complications are rare and medication has been shown to have minimal effect $[1,4,21]$.

\begin{tabular}{|lccc|}
\hline & Basal & 1- hour & 2- hours \\
\hline Glucose $(\mathrm{mg} / \mathrm{dl})$ & 113 & 204 & 184 \\
\hline Insulin $(\mathrm{uUl} / \mathrm{ml})$ & 12.1 & 89.4 & 129.8 \\
C-Peptide $(\mathrm{ng} / \mathrm{ml})$ & 1.04 & 7.86 & 9.71 \\
\hline
\end{tabular}

Fig. 2 OGTT include insulin and " $C$ " peptide results 

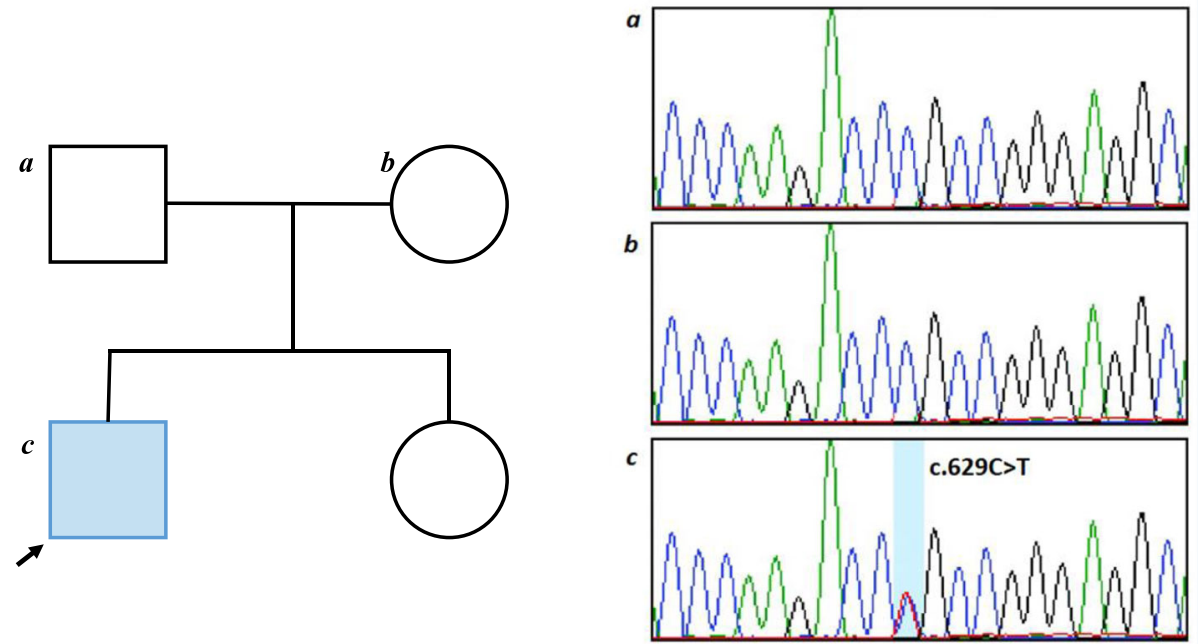

Fig. 3 Heterozygous pathogenic variant c.629C>T p.(Thr210Met). in GCK gene

It was interesting to mention that parents were negative for the mutation in the genetic analysis. Thus, suggested that the mutation diagnosed might be "de novo". Frequently, MODY diabetes is present in at least two consecutive generations, although this is not a good discriminator from young patients with Type 2 diabetes $[20,21]$. Few de novo mutations have been reported, suggesting a low prevalence $[6,8]$. Nevertheless, in the recent years the views on prevalence have been changing, and new publications suggest that de novo mutations could be more frequent than deduced from previously available [8]. A recent report in a LatinAmerican country, showed that $14 \%$ of GCK-MODY cases were de novo [6].

\section{Conclusion}

This is the first case of Diabetes MODY with a pathogenic variant in the GCK gene reported in Perú. Heterogeneity of diabetes presentations should make us suspect MODY in patients who cannot be characterized as classical patients with type 1 or 2 Diabetes. Because of rarely tested of these cases, we have not a complete information about the frequency of Other specific types of diabetes in Latin America.

A complete medical evaluation should be the first step to classify the patient, however the genetic evaluation of a clinical suspicion of MODY diabetes is important to confirm the diagnosis and establish an adequate treatment in patients.

\section{Abbreviations}

GAD: Glutamic acid decarboxylase; GCK: Glucokinase; MODY: Maturity-Onset Diabetes of the Young; OGTT: Oral glucose tolerance test

\section{Acknowledgements}

We thank Robert W. de Deugd and Diana Torres, from CENTOGEN, for the collaboration in the genetic study.

\section{Author's contributions}

Dr. Lizarzaburu-Robles was involved in management of case, drafting and revision of manuscript. Dr. Castro-Mujica and Gomez-de-la-Torres were involved in the literature review and revision of the manuscript. Dr.Vento, Villanes and Salsavilca were involved in management of case and checking the laboratory tests. Dr. Guerin was involved in the final revision of the manuscript. All authors read and approved the final manuscript.

\section{Funding}

This research did not receive any specific grant from any funding agency in the public, commercial or not-for-profit sector.

\section{Availability of data and materials}

The data used in this case report are available in the patient's medical record and can be disclosed by the corresponding author on reasonable request.

\section{Ethics approval and consent to participate}

Not applicable' for that section. There is no Ethics approval and consent to participate as this is a single case report.

\section{Consent for publication}

Written informed consent was obtained by the parents of patient.

\section{Competing interests}

The authors declare that they have no competing interests.

\section{Author details}

${ }^{1}$ Hospital Central de la Fuerza Aérea del Perú, Lima, Peru. ${ }^{2}$ Asociación para la Prevención, Educación e Investigación en Diabetes - APREDIAB, Lima, Peru. ${ }^{3}$ Sequence Reference Lab, Lima, Peru. ${ }^{4}$ Advanced Metabolic Care and Research San Diego, San Diego, USA.

Received: 7 October 2019 Accepted: 17 December 2019

Published online: 14 January 2020

\section{References}

1. Fajans SS, Bell GI. MODY: history, genetics, pathophysiology, and clinical decision making. Diabetes Care. 2011:34(8):1878-84.

2. American Diabetes Association. Classification and diagnosis of diabetes: standards of medical care in diabetes-2018. Diabetes Care. 2018; 41(Supplement 1):S13-S27. 
3. Naylor R, Knight Johnson A, del Gaudio D. Maturity-onset diabetes of the young overview. 2018. In: Adam MP, Ardinger HH, Pagon RA, et al., editors. GeneReviews ${ }^{\oplus}$ [Internet]. Seattle (WA): University of Washington, Seattle; 1993-2019.

4. Blanco Carrasco AJ. ¿Por qué debemos preocuparnos de diagnosticar una diabetes monogénica? Avances en Diabetología. Septiembre de. 2013;29(5): 126-32.

5. Carmody D, et al. GCK-MODY in the US National Monogenic Diabetes Registry: Frequently misdiagnosed and unnecessarily treated. Acta Diabetol. 2016;53(5):703-8.

6. Lopez A, et al. Analysis of mutations in the glucokinase gene in people clinically characterized as MODY2 without a family history of diabetes. Diabetes Res Clin Pract. 2016;118:38-43.

7. Pollak $\mathrm{C}$, et al. Diabetes mellitus por mutación en el gen de glucokinasa. Caso clínico Rev Med Chile. 2017:145:1203-7.

8. Stanik J, et al. De novo mutations of GCK, HNF1A and HNF4A may be more frequent in MODY than previously assumed. Diabetologia. 2014;57:480-4.

9. Bonfanti $\mathrm{R}$, et al. Residual beta-cell function and spontaneous clinical remission in type 1 diabetes mellitus: the role of puberty. Acta Diabetol. 1998:35:91-5.

10. Moole $\mathrm{H}$, et al. Spontaneous complete remission of type 1 diabetes mellitus in an adult-review and case report. J Community Hosp Intern Med Perspect. 2015;5:28709.

11. Davis EA, et al. Mutants of glucokinase cause hypoglycaemia- and hyperglycaemia syndromes and their analysis illuminates fundamental quantitative concepts of glucose homeostasis. Diabetologia. 1999:42:1175-86.

12. Osbak KK, et al. Update on Mutations in Glucokinase (GCK), Which CauseMaturity-Onset Diabetes of the Young, Permanent Neonatal Diabetes, and Hyperinsulinemic Hypoglycemia. Hum Mutat. 2009;30(11):1512-26.

13. Harris DN, et al. Evolutionary genomic dynamics of Peruvians before, during, and after the Inca Empire. Proc Natl Acad Sci USA. 2018;115(28):E6526E6535.

14. Estica $\mathrm{R}$, et al. Hallazgo de una nueva mutación en una familia chilena con diabetes monogénica. Caso clínico Rev Med Chile. 2018;146:929-32.

15. Carlsson A, et al. Absence of islet autoantibodies and modestly raised glucose values at Diabetes Diagnosis Should Lead to Testing for MODY: Lessons From a 5-Year Pediatric Swedish National Cohort Study. Diabetes Care. 2020:43:82-9.

16. Wędrychowicz A, et al. Phenotype heterogeneity in Glucokinase-maturityonset diabetes of the young (GCK-MODY) patients. J Clin Res Pediatr Endocrinol. 2017;9(3):246-52.

17. Bjornstad et al. Metformin improves insulin sensitivity and vascular health in youth with type 1 diabetes mellitus. Circulation. 2018;138(25):2895-907.

18. Giannarelli $R$, et al. Reducing insulin resistance with metformin: the evidence today. Diabetes Metab. 2003;29(4, Part 2):6528-35.

19. Juszczak $A$, et al. When to consider a diagnosis of MODY at the presentation of diabetes: aetiology matters for correct management. Br J Gen Pract. 2016:66(647):e457-9.

20. McDonald T, Ellard S. Maturity onset diabetes of the young: identification and diagnosis. Ann Clin Biochem. 2013;50(5):403-15.

21. Xie $\mathrm{F}$, et al. Precision medicine in diabetes prevention, classification and management. J Diabetes Investig. 2018;9:998-1015.

\section{Publisher's Note}

Springer Nature remains neutral with regard to jurisdictional claims in published maps and institutional affiliations.

Ready to submit your research? Choose BMC and benefit from:

- fast, convenient online submission

- thorough peer review by experienced researchers in your field

- rapid publication on acceptance

- support for research data, including large and complex data types

- gold Open Access which fosters wider collaboration and increased citations

- maximum visibility for your research: over $100 \mathrm{M}$ website views per year

At BMC, research is always in progress.

Learn more biomedcentral.com/submissions 